08.1

\title{
Синтез наночастиц титана в жидком ксеноне с помощью высоковольтного электрического разряда
}

(ㄷ Д.Ю. Акимов ${ }^{1,2}$, В.А. Белов ${ }^{1,2}$, А.И. Болоздыня ${ }^{1}$, С.В. Бобков ${ }^{3}$, А.А. Васин ${ }^{1}$, Н.В. Волков ${ }^{1}$, А.В. Галаванов ${ }^{1}$, Ю.В. Гусаков ${ }^{1,4}$, П.C. Джумаев ${ }^{1}$, D.E. Kdib ${ }^{1}$, А.Г. Коваленко ${ }^{1,2}$, E.C. Козлова ${ }^{1}$, М.Ю. Колпаков ${ }^{3}$, А.М. Коновалов ${ }^{1,2,5}$, А.В. Кумпан ${ }^{1}$, А.В. Лукьяшин ${ }^{1,2}$, Ю.А. Меликян ${ }^{1}$, О.Е. Непочатая ${ }^{1}$, Д.Г. Рудик ${ }^{1,2}$, М.Ю. Савинов ${ }^{3}$, Г.Е. Симаков ${ }^{1,2,5}$, В.В. Сосновцев ${ }^{1}$, А.В. Хромов ${ }^{1}$, А.В. Шакиров ${ }^{1, \uparrow}$

${ }^{1}$ Национальный исследовательский ядерный университет „МИФИ“, Москва, Россия

${ }^{2}$ Национальный исследовательский центр „Курчатовский институт“, Москва, Россия

${ }^{3}$ ООО „Хром“, Москва, Россия

${ }^{4}$ Объединенный институт ядерных исследований, Дубна, Московская обл., Россия

${ }^{5}$ Московский фризико-технический институт (Государственный университет), Долгопрудный, Московская обл., Россия

ฯ E-mail: shalexey91@mail.ru

Поступило в Редакцию 16 марта 2018 г.

Обнаружено образование наночастиц титана при высоковольтном электрическом разряде между титановыми электродами в жидком ксеноне при температуре $-105^{\circ} \mathrm{C}$. Показано, что наночастицы титана имеют сферическую форму со средним диаметром $<50 \mathrm{~nm}$ и обладают высокой химической активностью, что позволяет при достижении их относительной массовой концентрации $\sim 10^{-6}$ эффективно очищать ксенон от электроотрицательных примесей для его использования в качестве рабочей среды высокоэффективных детекторов ядерных излучений нового поколения.

DOI: 10.21883/PJTF.2018.14.46347.17300

В последние несколько десятилетий наблюдается значительный прогресс в исследованиях наноматериалов, их уникальных электри- 
ческих, оптических, магнитных и каталитических свойств [1]. Особое внимание уделяется синтезу металлических наночастиц и исследованию их свойств [2]. В частности, показано, что в газовых средах химическая активность нанодисперсного титана значительно превышает химическую активность стандартных неиспарительных геттеров на основе губчатого титана с микронным размером пор [3]. По этой причине разрабатываются методы генерации наночастиц титана в инертных газах [4]. Известен также искровой метод очистки сжиженных благородных газов, основанный на генерации мелкодисперсного титана электрическим разрядом $[5,6]$. Согласно опубликованным данным, для синтеза металлических наночастиц в жидких средах обычно используются жидкости типа дистиллированной воды, этанола или растворов солей металлов в воде [1].

В настоящей работе впервые наблюдалось образование наночастиц (НЧ) титана в макроскопических образцах жидкого ксенона. Экспериментальная установка представляет собой криостат из нержавеющей стали, в котором можно сконденсировать до 1001 ксенона общей массой до $300 \mathrm{~kg}$ [7]. Для распыления титана в жидком ксеноне использовалась двухэлектродная разрядная система типа „лезвие-плоскость“ с межэлектродным промежутком порядка $1 \mathrm{~mm}$. Электроды изготовлены из титанового листового проката марки ВТ1-0 толщиной $1.5 \mathrm{~mm}$. Высоковольтный катод („лезвие“) выполнен в форме цилиндра диаметром $20 \mathrm{~cm}$ и высотой $3 \mathrm{~cm}$; заземленный анод („плоскость“) в форме плоского кольца. Разрядная цепь формировалась с помощью высоковольтного кабеля длиной $6 \mathrm{~m}$ и емкостью $600 \mathrm{pF}$ и высоковольтного источника постоянного тока ВС20-10, как показано на рис. 1,a. Типичная вольт-амперная характеристика высоковольтного разряда в жидком ксеноне приведена на рис. $1, b$. Осциллограмма разрядного тока представлена на рис. $1, c$. В случае достаточно чистого ксенона (когда время жизни электронов до захвата электроотрицательными (ЭО) примесями превышает $10 \mu \mathrm{s}$ ) на вольт-амперной зависимости отчетливо проявляется относительно низковольтная ветвь коронного разряда, переходящего в искровой пробой при повышении напряжения между электродами выше $12.5 \mathrm{kV}$.

С помощью импульсной рентгеновской ионизационной камеры, установленной в разрядной камере, контролировалась степень загрязненности жидкого ксенона ЭО-примесями по времени жизни квазисвободных электронов до захвата [7]. Для исследования использовались образцы

Письма в ЖТФ, 2018, том 44, вып. 14 

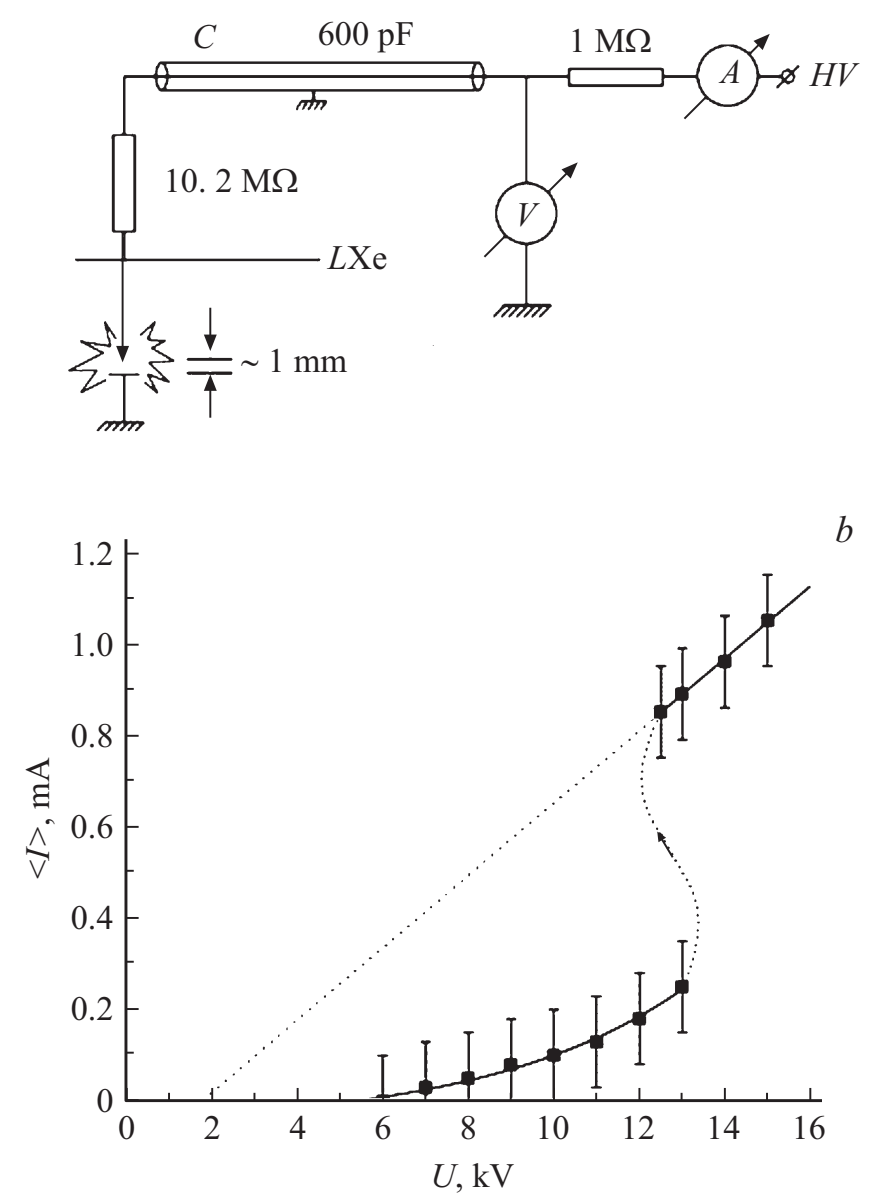

Рис. 1. $a-$ схема разрядной цепи $(C-$ кабель емкостью $600 \mathrm{pF}, L \mathrm{Xe}-$ уровень жидкого ксенона, $H V$ - высокое напряжение), $b-$ вольт-амперная характеристика разряда, $c$ - осциллограмма разрядного тока.

жидкого ксенона массой от 10 до $205 \mathrm{~kg}$. При средней мощности разряда $2 \mathrm{~W}$ необходимо было не менее $50 \mathrm{~h}$ работы разрядника для того, чтобы началось заметное увеличение времени жизни квазисвободных

Письма в ЖТФ, 2018, том 44, вып. 14 


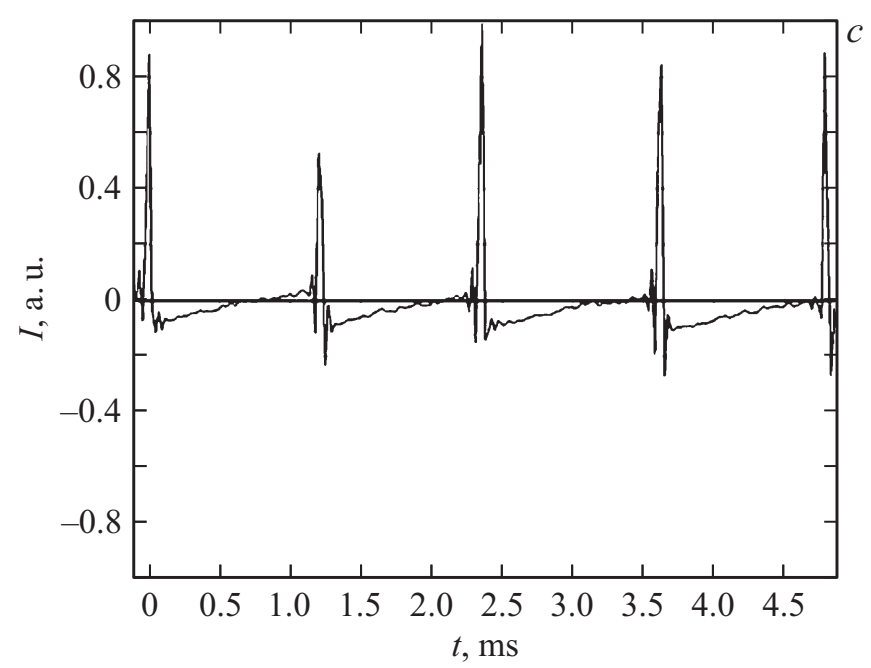

Рис. 1 (продолжение).

электронов в полях дрейфа напряженностью 10-500 V/cm от исходного значения, много меньшего $1 \mu \mathrm{s}$, до более чем $100 \mu \mathrm{s}$ на конечной стадии эксперимента. Время жизни квазисвободных электронов до захвата ЭО-примесями росло по экспоненциальному закону со скоростью

$$
\tau_{e}=\tau_{0} \exp \left(t / t_{0}\right)
$$

где $t_{0} \approx 40 \mathrm{~h}$. После удаления ксенона и вскрытия камеры титановая пыль анализировалась с помощью сканирующего электронного микроскопа Carl Zeiss EVO 50. Было обнаружено, что в жидком ксеноне описанным выше способом производится титановая пыль, состоящая из НЧ, форма которых близка к сферической (рис. 2), а средний диаметр не превышает $50 \mathrm{~nm}$.

Методом энергодисперсионной рентгеновской спектроскопии был определен элементный состав НЧ. Обнаружено, что НЧ в основном состоят из титана (рис. 3). Присутствие кислорода, вероятно, связано со взаимодействием электроотрицательных примесей в жидком ксеноне с химически чистой поверхностью НЧ титана. Присутствие серебра объясняется серебряным покрытием металлической подложки, на которую осаждалась титановая пыль. 


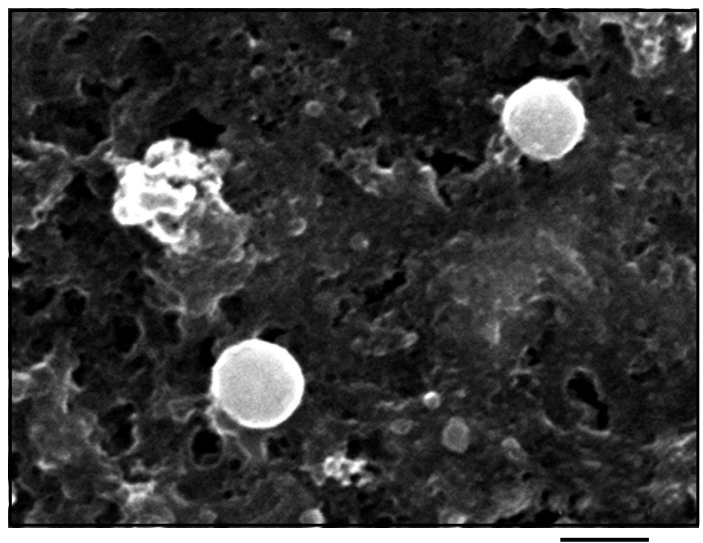

$\overline{300 \mathrm{~nm}}$

Pис. 2. Изображение наночастиц титана, осевших на покрытую серебром медную прокладку после испарения жидкого ксенона, полученное с помощью сканирующего электронного микроскопа Carl Zeiss EVO 50.

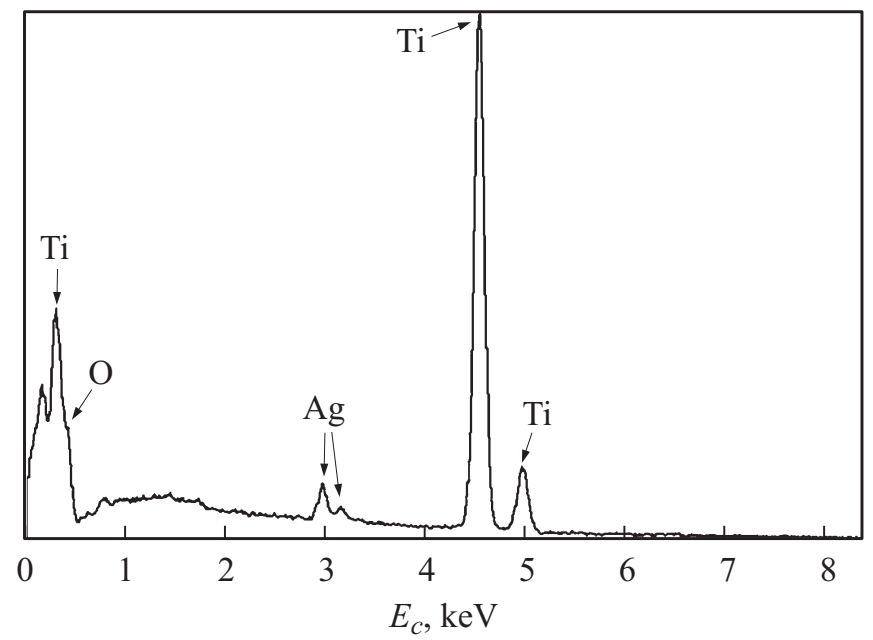

Рис. 3. Элементный состав наночастиц титана, измеренный с помощью сканирующего электронного микроскопа Carl Zeiss EVO 50 методом энергодисперсионной рентгеновской спектроскопии. $E_{c}$ - энергия характеристического излучения.

Письма в ЖТФ, 2018, том 44, вып. 14 
Содержание молекулярных примесей (в ppm) в ксеноне до и после процедуры очистки нанодисперсным титаном

\begin{tabular}{l|c|c|c|c|c|c|c|c|c}
\hline \multirow{2}{*}{$\begin{array}{l}\text { Содержание } \\
\text { примесей }\end{array}$} & \multicolumn{7}{|c}{ Примесь } \\
\cline { 2 - 8 } & $\mathrm{H}_{2}$ & $\mathrm{~N}_{2}$ & $\mathrm{O}_{2}$ & $\mathrm{CF}_{4}$ & $\mathrm{CH}_{4}$ & $\mathrm{CO}_{2}$ & $\mathrm{H}_{2} \mathrm{O}$ & $\mathrm{SF}_{6}$ & $\mathrm{C}_{n} \mathrm{H}_{m} \mathrm{R}_{k}$ \\
\hline $\begin{array}{l}\text { Исходный } \\
\text { образец }\end{array}$ & 0.325 & 0.950 & 0.180 & $<0.001$ & 0.210 & 0.835 & 1.4 & 0.015 & 7.450 \\
$\begin{array}{l}\text { После } \\
\text { очистки }\end{array}$ & 0.600 & 0.700 & 0.050 & $<0.001$ & 0.065 & 0.015 & 1.0 & $<0.0001$ & 1.520
\end{tabular}

Эффективность пароизводства нанодисперсного титана составляла $60 \mu \mathrm{g} / \mathrm{C}$ в образцах жидкого ксенона массой несколько десятков килограмм, что примерно соответствует эффективности производства титанового геттера в работе Покачалова и др. [8] в образцах жидкого ксенона массой порядка $100 \mathrm{~g}$.

Анализ количества произведенных НЧ показал, что начало эффективного поглощения ЭО-примесей соответствует достижению массовой концентрации НЧ порядка $1.2 \mathrm{mg} / \mathrm{l}$ в жидком ксеноне, что соответствует примерно $100 \mathrm{mg}$ общей массы произведенных НЧ в эксперименте c $205 \mathrm{~kg}$ жидкого ксенона. Общая площадь поверхности наночастиц при этом составляла $\sim 5 \mathrm{~m}^{2}$. Это означает, что отношение массы геттера на основе НЧ титана к его эффективной площади на несколько порядков меньше, чем у широко известного горячего металлического геттера типа St122 (Ti-St707) производства компании SAES Pure Gases, который не мог обеспечить очистку ксенона, загрязненного высокомолекулярными примесями и элегазом в исходном газе в концентрациях, указанных в таблице. Таким образом, показано, что НЧ титана могут использоваться для очистки макроскопических образцов жидкого ксенона, применяемых в качестве рабочих сред современных детекторов ядерных излучений и элементарных частиц $[6,7]$.

Работа выполнена при поддержке Программы повышения конкурентоспособности НИЯУ МИФИ (02.a03.21.0005).

Авторы выражают благодарность В.Ф. Петрунину за труд прочтения рукописи статьи и ценные критические замечания, позволившие существенно улучшить изложение материала.

Письма в ЖТФ, 2018, том 44, вып. 14 


\section{Список литературы}

[1] Saito G., Akiyama T. // J. Nanomaterials. 2015. V. 2015. P. 123696 (1-21).

[2] Chen Q., Li J., Li Y. // J. Phys. D.: Appl. Phys. 2015. V. 48. P. 424005 (1-26).

[3] Park M.Y., Ha H., Kim W.B., Park J.S., Suh C.Y., Woo S.B. // Solid State Phenom. 2007. V. 124-126. P. 1281-1284.

[4] Phillips J., Perry W.L., Kroenke W.J. Method for producing metallic nanoparticles. USA Patent N US 6,689,192 B1. Feb. 10, 2004.

[5] Ободовский И.М., Покачалов С.Г., Шилов В.А. // ЖТФ. 1980. Т. 50. С. 2028 2030.

[6] Aprile E., Bolotnikov A.E., Bolozdynya A.I., Doke T. Noble gas detectors. Weinheim: Wiley-VCH Verlag, 2006. 345 p.

[7] Акимов Д.Ю., Белов В.А., Бердникова А.К., Бобков С.В., Болоздыня А.И., Гусаков Ю.В., Гусс Д.В., Джумаев П.С., Долголенко А.Г., Коваленко А.Г., Козлова Е.С., Колпаков М.Ю., Коновалов А.М., Крахмалова Т.Д., Кумпан А.В., Лукьяшин А.В., Меликян Ю.А., Непочатая О.Е., Рудик Д.Г., Савинов М.Ю., Сидоренко А.В., Симаков Г.Е., Сосновцев В.В., Таэр Г.С., Хромов А.В., Шакиров А.В. // Приборы и техника эксперимента. 2017. № 6. C. $16-22$.

[8] Pokachalov S.G., Kirsanov M.A., Kruglov A.A., Obodovski I.M. // Nucl. Instrum. Meth. A. 1993. V. 327. P. 159-162.

Письма в ЖТФ, 2018, том 44, вып. 14 